University of Nebraska - Lincoln

DigitalCommons@University of Nebraska - Lincoln

U.S. National Park Service Publications and

Papers

National Park Service

2008

\title{
Multiple Data Sources Improve DNA-Based Mark-Recapture Population Estimates of Grizzly Bears
}

\author{
John Boulanger \\ Integrated Ecological Research, boulange@ecological.bc.ca \\ Katherine C. Kendall \\ USGS-NRMSC Science Center, kkendall@usgs.gov \\ Jeffrey B. Stetz \\ University of Montana, jeff.stetz@gmail.com \\ David A. Roon \\ University of Idaho, droon@uidaho.edu \\ Lisette P. Waits \\ University of IdahoUniversity of Idaho, Iwaits@uidaho.edu \\ See next page for additional authors
}

Follow this and additional works at: https://digitalcommons.unl.edu/natlpark

\footnotetext{
Boulanger, John; Kendall, Katherine C.; Stetz, Jeffrey B.; Roon, David A.; Waits, Lisette P.; and Paetkau, David, "Multiple Data Sources Improve DNA-Based Mark-Recapture Population Estimates of Grizzly Bears" (2008). U.S. National Park Service Publications and Papers. 50.

https://digitalcommons.unl.edu/natlpark/50
}

This Article is brought to you for free and open access by the National Park Service at DigitalCommons@University of Nebraska - Lincoln. It has been accepted for inclusion in U.S. National Park Service Publications and Papers by an authorized administrator of DigitalCommons@University of Nebraska - Lincoln. 


\section{Authors}

John Boulanger, Katherine C. Kendall, Jeffrey B. Stetz, David A. Roon, Lisette P. Waits, and David Paetkau 


\title{
MULTIPLE DATA SOURCES IMPROVE DNA-BASED MARK-RECAPTURE POPULATION ESTIMATES OF GRIZZLY BEARS
}

\author{
John Boulanger,${ }^{1,6}$ Katherine C. Kendall,${ }^{2}$ Jeffrey B. Stetz,${ }^{3}$ David A. Roon,${ }^{4}$ Lisette P. Waits, ${ }^{4}$ \\ AND DaVid PAETKAU ${ }^{5}$ \\ ${ }^{1}$ Integrated Ecological Research, 924 Innes Street, Nelson, British Columbia V1L 5 T2 Canada \\ ${ }^{2}$ U.S. Geological Survey, Northern Rocky Mountain Science Center, Glacier Field Station, Glacier National Park, \\ West Glacier, Montana 59936 USA \\ ${ }^{3}$ Cooperative Ecosystem Studies Unit, University of Montana, Glacier Field Station, Glacier National Park, \\ West Glacier, Montana 59936 USA \\ ${ }^{4}$ Department of Fish and Wildlife, University of Idaho, Moscow, Idaho 83844-1136 USA \\ ${ }^{5}$ Wildlife Genetics International, P.O. Box 274, Nelson, British Columbia V1L 5 P9 Canada
}

\begin{abstract}
A fundamental challenge to estimating population size with mark-recapture methods is heterogeneous capture probabilities and subsequent bias of population estimates. Confronting this problem usually requires substantial sampling effort that can be difficult to achieve for some species, such as carnivores. We developed a methodology that uses two data sources to deal with heterogeneity and applied this to DNA mark-recapture data from grizzly bears (Ursus arctos). We improved population estimates by incorporating additional DNA "captures" of grizzly bears obtained by collecting hair from unbaited bear rub trees concurrently with baited, grid-based, hair snag sampling. We consider a Lincoln-Petersen estimator with hair snag captures as the initial session and rub tree captures as the recapture session and develop an estimator in program MARK that treats hair snag and rub tree samples as successive sessions. Using empirical data from a large-scale project in the greater Glacier National Park, Montana, USA, area and simulation modeling we evaluate these methods and compare the results to hair-snag-only estimates. Empirical results indicate that, compared with hair-snag-only data, the joint hair-snag-rub-tree methods produce similar but more precise estimates if capture and recapture rates are reasonably high for both methods. Simulation results suggest that estimators are potentially affected by correlation of capture probabilities between sample types in the presence of heterogeneity. Overall, closed population Huggins-Pledger estimators showed the highest precision and were most robust to sparse data, heterogeneity, and capture probability correlation among sampling types. Results also indicate that these estimators can be used when a segment of the population has zero capture probability for one of the methods. We propose that this general methodology may be useful for other species in which mark-recapture data are available from multiple sources.
\end{abstract}

Key words: bear rub trees; DNA; Glacier National Park, Montana, USA; grizzly bears; hair sampling; mark-recapture; mixture models; noninvasive genetic sampling; population estimation; program MARK; Ursus arctos.

\section{INTRODUCTION}

One of the fundamental challenges to estimating population size using mark-recapture methodology is heterogeneous capture probabilities of animals within the sampled population (Otis et al. 1978, Seber 1982) and subsequent bias in estimates of population size and associated variance (Seber 1982). Various mark-recapture estimators have been developed that are robust to heterogeneity (Williams et al. 2002); however, these often have stringent sampling requirements such as the need to conduct many $(\geq 5)$ sequential sampling sessions (Otis et al. 1978). In addition, estimates may still be biased if inappropriate models are selected when capture

Manuscript received 22 November 2006; revised 28 August 2007; accepted 22 October 2007. Corresponding Editor: N. T. Hobbs.

${ }^{6}$ E-mail: boulange@ecological.bc.ca probabilities for a segment of the population approach zero (Boulanger et al. 2004b). One way to confront heterogeneity is to use multiple methods to sample the population, thereby minimizing the impact of heterogeneity caused by any one method (Williams et al. 2002). Simultaneous application of multiple sampling methods also has potential to reduce sampling costs by increasing fieldwork efficiency, especially for studies of large carnivores and other species with logistically challenging sampling designs.

In this paper we consider study designs for estimating grizzly bear population size using multiple DNA sampling methods. Hair snag DNA-based mark-recapture methods have been used to estimate grizzly bear (Ursus arctos) and black bear (U. americanus) populations at unprecedented scales and levels of precision and in previously inaccessible geographic regions in British Columbia, Alberta, and the United States since 1996 
(Woods et al. 1999, Boulanger et al. 2002, Boersen et al. 2003, Triant et al. 2004, Mowat et al. 2005). However, successful grid-based hair snag sampling must be of sufficient intensity to produce high recapture rates, is expensive to conduct, and can result in estimates with low levels of precision in large-scale projects (Boulanger et al. 2002).

We became interested in collecting hair from naturally occurring bear rub trees as a complementary method of sampling bear populations based on the prevalence of rub trees and hair encountered during bear sign inventories in Glacier National Park (GNP) 1984-1997 (Kendall et al. 1992). Rubbing is a natural behavior of grizzly and black bears range-wide (Burst and Pelton 1983, Green and Mattson 2003) (see Plate 1). As such, bear rub surveys may target a different segment of the population compared to methods that use attractants and may avoid behavioral responses to baited sites or aversion due to previous live capture. Collecting hair from bear rubs found on trails is inexpensive relative to implementing a hair snag grid, and efficiencies can be realized by field crews collecting from rubs while en route to hair snags. During pilot surveys in 1997, we found that placing short pieces of barbed wire on the rub surface improved hair collection from rub trees and did not appear to discourage rubbing. As a result, we collected hair concurrently from barbed wire on unbaited bear rubs and baited hair snag corrals during a study to estimate the density of the grizzly bear population in the greater Glacier National Park area (Greater Glacier Area, GGA).

Heterogeneity is present in grizzly bear mark-recapture data due to factors that cannot be identified from DNA, such as bear age and reproductive status. Given this, we explore strategies to combine hair snag and rub tree data to improve DNA mark-recapture population estimates for grizzly bears. First, we use the LincolnPetersen (LP; Lincoln 1930) estimator with the number of individuals identified by hair snag sampling as one session and individuals identified by rub tree sampling as the other session. The LP estimator is potentially robust (unbiased) to capture probability heterogeneity inherent to each form of capture as long as capture probabilities from the two capture types are independent (Williams et al. 2002). In fact, unbiased estimates are possible even if the capture probabilities of some bears are zero for one capture method as long as all capture probabilities are above zero for the other form of capture (Seber 1982). However, if capture probabilities are not independent it is likely the LP estimator will be biased. In addition, because data is pooled for each method, the LP estimator discards information on individual heterogeneity associated with each sampling method. Therefore, we also investigated the Huggins (Huggins 1991) closed model estimators in program MARK (White and Burnham 1999) to assess potential gains in robustness and precision when session-specific models are used.
One potential advantage of multiple sampling methods is that the robustness to capture probability variation potentially reduces the need to conduct multiple sessions of sampling (to allow modeling of capture probability variation). Much of the cost of DNA sampling is due to the need to access remote sites in synchronized sessions through the use of helicopters or large ground crews. The use of joint modeling could result in an overall reduction of field efforts and expenses. The conditional form of the LP estimator and the closed MARK models are increasingly complex forms of a general mark-recapture closed model estimator. For example, the LP model is analogous to a two-session closed model estimator with time-varying capture probabilities (Otis et al. 1978, Huggins 1991). The fundamental question becomes whether the gains in robustness by session-specific sampling (and increasing model complexity) justify the additional expense when joint methods are used. We explored robustness of methods using Monte Carlo simulation and comparison of joint hair-snag-rub-tree methods with hair-snag-only methods.

We suggest that the general method of incorporating multiple data sources to estimate population size could be applied to other species. For example, species are often identified during mark-recapture estimation projects by genotyping scats, live capture, or incidental sightings. We argue that this approach may enhance precision and accuracy of estimates and simplify field sampling for these types of projects as well.

The data used in this paper were collected as part of the Greater Glacier Area Bear DNA Project, a multiyear, multi-agency effort led by the U.S. Geological Survey. Because some models have been simplified in order to focus on modeling issues, the estimates of population size presented in this paper differ slightly from final estimates for this area generated using more complex models (K. C. Kendall, unpublished manuscript).

\section{Methods \\ Study area}

Our study encompassed two nested study areas straddling the Continental Divide in northwestern Montana, USA (Fig. 1). The $7993-\mathrm{km}^{2}$ Greater Glacier Area (GGA) is bounded on the north by the United States-Canada border and on the west by Highways 2 and 93. The eastern, southern, and western flanks include parts of the Blackfeet Indian Reservation, the Lewis and Clark National Forest, and the Flathead and Kootenai National Forests, respectively. The Glacier National Park (GNP) study area covered the center 50\% of the GGA.

\section{Field methods}

Two bear hair sampling methods were employed simultaneously: hair snags and rub trees (Fig. 1). Barbed-wire hair snags baited with a scent lure were 


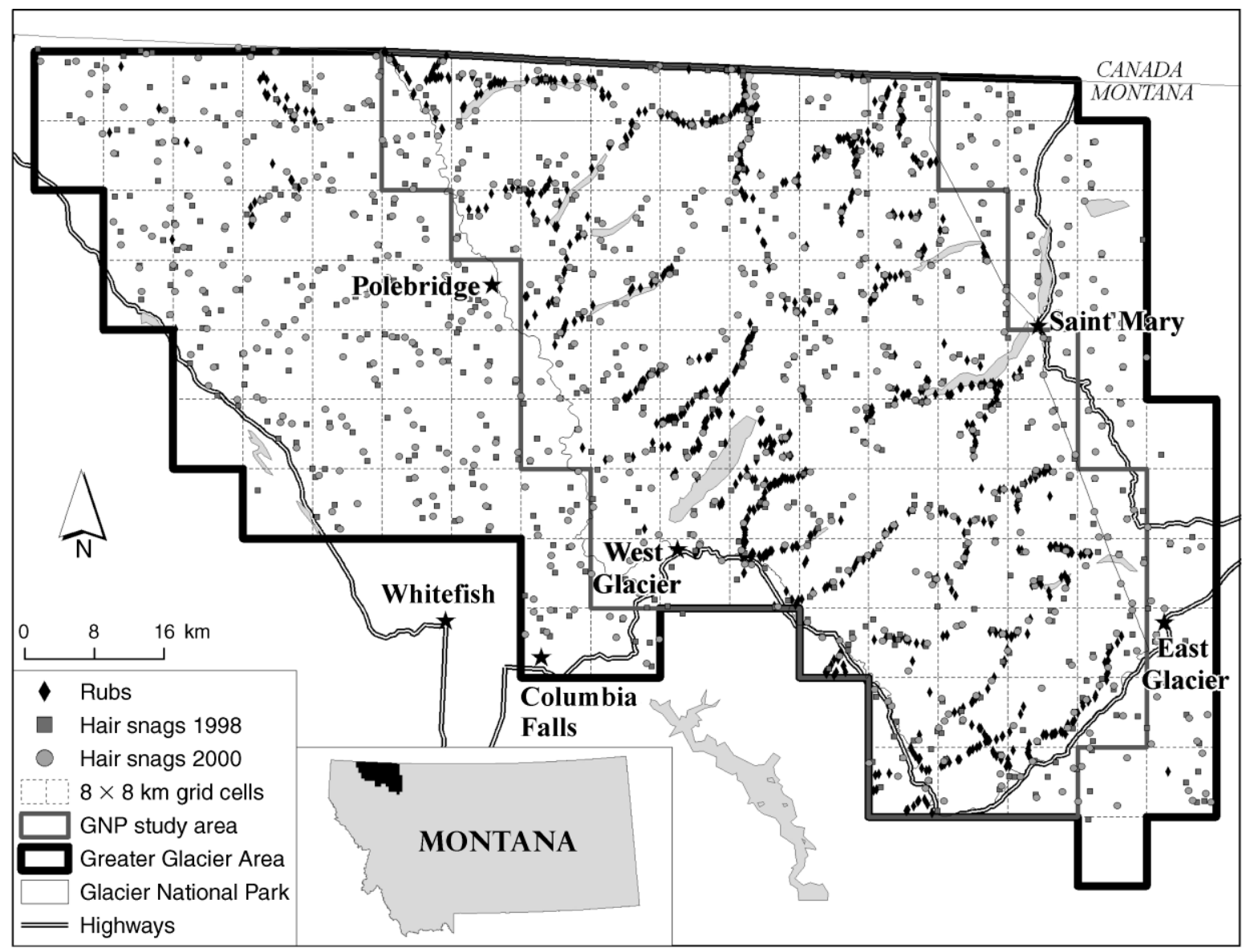

FIG. 1. Location of bear hair snags distributed within an $8 \times 8 \mathrm{~km}$ grid and bear rub trees surveyed in the nested Glacier National Park (GNP) and Greater Glacier (GGA) study areas, Montana, USA, 1998 and 2000.

distributed systematically on an $8 \times 8 \mathrm{~km}$ grid throughout the GGA. These were deployed in each of 126 grid cells during five 14-d sessions beginning in midMay, following protocols similar to Woods et al. (1999). Hair snags were moved at least $1 \mathrm{~km}$ within cells between sessions to decrease the likelihood of a declining trap response over time. To collect hair from rub trees, we surveyed hiking trails in $\operatorname{GNP}(1998,2000)$ and, at a lower intensity, surrounding forestlands (2000). Barbed wire (but no attractant) was attached to the rub trees to facilitate hair collection. All hair was removed from the barbed wire during sampling to ensure that hair found during subsequent visits had been deposited since the last survey. Rub trees were checked at less frequent and regular intervals than hair snags. Session dates for rub tree surveys were based upon the 14-d interval (corresponding to hair snag sessions) in which samples were collected.

\section{Genetic methods}

Species, individual identity, and gender of bears were determined through analysis of DNA extracted from the hair samples (Woods et al. 1999). Six nuclear microsat- ellite loci were used to define unique individuals: G1A, G10B, G10C, G10L, G10M, and G10P (Paetkau et al. 1995). Up to 10 additional loci were analyzed for at least one sample from each individual. Of the 290 individual grizzly bears used in this analysis, $97 \%$ had $\geq 9$-locus genotypes, and, when all available loci were considered, all individual bears differed at four or more loci. Gender was initially assigned using the SRY marker (Taberlet et al. 1993) and independently verified with the amelogenin marker (Ennis and Gallagher 1994). Exhaustive efforts to minimize errors were undertaken following the procedures of Paetkau (2003), Roon et al. (2005), Waits and Paetkau (2005), and K. C. Kendall (unpublished manuscript).

\section{Data analysis}

Capture histories for individual bears were used in mark-recapture models to estimate population size. We compared population estimates from models using hairsnag (HS)-only data and joint hair-snag-rub-tree (HSRT) data. We also calculated rub-tree (RT)-only estimates for GNP to address the possibility of using rub trees as a stand-alone sampling method. For the HSRT 
data, we used the bias-corrected LP estimator (Lincoln 1930, Seber 1982) with HS captures pooled as the initial session $\left(n_{1}\right)$ and RT captures pooled as the second session $\left(n_{2}\right)$. Bears identified using both methods represented marked bears in the second sample $\left(m_{2}\right)$. We also used the Huggins-Pledger (HUPL) closed mixture models (Huggins 1991, Pledger 2000) in program MARK for HSRT and HS-only data. For the HSRT-HUPL model, we entered HS session data followed by RT session data. For example, for the 1998 and 2000 GNP data, sessions 1-5 were from hair snags and sessions 6-11 were from RT surveys. This approach allowed consideration of sampling type using one encounter history entry per animal and is theoretically acceptable under the assumption of independence of HS and RT samples. For our application, the order of sessions only affects estimates if a behavioral response is present in the data. We assumed behavioral response was minimal in our data because hair snag sites were moved between sessions (Boulanger et al. 2006) and because use of rub trees by bears is a natural behavior. The sex of each bear was entered as a group covariate. Differences in capture probabilities for each sampling type were modeled as time variation. For example, a heterogeneity model with sex-specific capture probabilities for hair snag and rub tree sampling, $M_{\mathrm{h}}(\operatorname{sex} \times$ type $)$, was formulated by constraining (using the design matrix in MARK) capture probabilities to be unique for sessions 1-5 and 6-11 for both males and females. Heterogeneity that could not be explained by identifiable factors (e.g., sex) was modeled using a mixture model approach. Our $M_{\mathrm{h}}$ mixture models use a mixture of two capture probability distributions to model heterogeneity of a single capture probability distribution (Pledger 2000). The parameters are the probability that a given capture probability comes from the first distribution $(\pi)$, the mean capture probability of the first distribution $\left(\theta_{1}\right)$, and the mean capture probability of the second distribution $\left(\theta_{2}\right)$. From Carothers (1973), the mean capture probability $(\bar{\theta})$ (based on two-mixture distributions) and coefficient of variation for the mean capture probability $(\mathrm{CV}(\bar{\theta}))$ were estimated as $\bar{\theta}=\pi_{1} \theta_{1}+(1-$ $\left.\pi_{1}\right) \theta_{2}$ and $\operatorname{CV}(\bar{\theta})=\left[\sqrt{\pi_{1}\left(1-\pi_{1}\right)}\left|\theta_{1}-\theta_{2}\right|\right] / \bar{\theta}$. A higher $\operatorname{CV}(\bar{\theta})$ indicated a greater degree of heterogeneity in capture probabilities. Hair-snag- or rub-tree-specific mixture capture probabilities $\left(\theta_{i}\right)$ were modeled as additive $\beta$ terms with a logit link function. All mixture HSRT models assumed a common probability of mixture for HS and RT data types. By constraining the parameter index matrices in MARK we also introduced models that used mixtures for only one of the data types. Population estimates were obtained as a derived parameter from the Huggins estimator. We calculated log-based confidence intervals that incorporate the minimum number of bears known to be alive in the study area for both the Huggins and LP estimators (White et al. 2002). The Pledger (2000) estimator in
MARK was updated in May 2007; we used this version for all analyses and simulations.

The number of rub trees sampled and the number of days between successive rub tree hair collections for each tree varied for each sampling session. We used a rub tree effort (RTE) temporal covariate to model the time variation caused by varying rub tree sampling intensity in conjunction with mixture models to confront potential heterogeneity bias. Rub tree effort was the cumulative number of days between successive hair collections for all trees sampled per session.

Relative support of models was evaluated using the sample-size-adjusted Akaike Information Criterion $\left(\mathrm{AIC}_{\mathrm{c}}\right)$ index of model fit. The model with the lowest $\mathrm{AIC}_{\mathrm{c}}$ score was considered the model that best balanced bias and precision (Burnham and Anderson 1998). Changes in $\mathrm{AIC}_{\mathrm{c}}\left(\Delta \mathrm{AIC}_{\mathrm{c}}\right)$ values were used to evaluate the fit of models when $\mathrm{AIC}_{\mathrm{c}}$ scores were close. We deemed any model with a $\Delta \mathrm{AIC}_{\mathrm{c}}$ score of less than two worthy of consideration. The $\mathrm{AIC}_{\mathrm{c}}$ weights $\left(w_{i}\right)$ were calculated to determine the proportional support for each of the candidate models. Parameter estimates were averaged based on their support by the data as indexed by $\mathrm{AIC}_{\mathrm{c}}$ weights to further account for model selection uncertainty (Burnham and Anderson 1998).

\section{Simulations}

We used Monte Carlo simulation to evaluate the effects of several forms of heterogeneity variation on the HS and HSRT estimators. We considered two scenarios. In the first, all bears had capture probabilities greater than zero and we simulated different levels of mean capture probability, as well as varying correlation of HS and RT capture probabilities. In the second scenario, $33 \%$ of the bears had capture probabilities of zero in the RT sample (which was not correlated with HS capture probability). This corresponded to the GGA RT survey effort, in which $\sim 40 \%$ of the study area (with lower bear density) was not sampled with rub trees.

We used a bivariate normal distribution model to generate correlated capture probabilities. First, the desired mean capture probability $(p)$ and associated variance $(\operatorname{Var}(p))$ for hair snags $(X)$ was transformed to the logit scale $\left(X_{p}\right)$ using the equations $X_{p}=\ln (p /(1-p))$ and $\sigma_{x}=\sqrt{\operatorname{Var}(p) / p^{2}(1-p)^{2}}$ (Burnham et al. 1987). Then a normal random variate was generated for each simulated bear using the formula $X_{p}^{\prime}=X_{p}+\sigma_{x} Z_{1}$, where $\sigma_{x}$ was the standard deviation of $X_{p}$ and $Z_{1}$ was a standardized random normal variable. A correlated variate for rub trees $\left(Y_{p}^{\prime}\right)$ with the same mean and standard deviation as $X_{p}$ was then generated for the simulated bear using the formula $Y_{p}^{\prime}=X_{p}+r \sigma_{x} Z_{1}+$ $\sigma_{x} \sqrt{1-r^{2}} Z_{2}$ where $r$ was the correlation coefficient and $Z_{2}$ was a standardized random normal variable independent of $Z_{1}$ (Brown and Rothery 1993). Finally, $X_{p}^{\prime}$ and $Y_{p}^{\prime}$ were logistic transformed $\left(p_{X^{\prime}}=e^{X_{p}^{\prime}} /\left(1+e^{X_{p}^{\prime}}\right)\right)$ to ensure that probabilities ranged between 0 and 1 . We generated paired capture probabilities for hair snags and 
rub trees with varying mean levels, correlations, and dispersion (heterogeneity) by varying $p, r$, and $\sigma_{x}$. Dispersion was indexed by the coefficient of variation of $p_{x}\left(\mathrm{CV}_{p}=\operatorname{Var}(p)^{0.5} / p\right)$, which scaled dispersion for mean $p_{x}$ levels. Using the normal distribution to simulate heterogeneity is simplistic because it assumes a unimodal distribution of capture probabilities; using a more complex multimodal model would obscure the effects of correlated capture probabilities. In addition, our simulations assumed equal mean capture probabilities between HS and RT sampling and no temporal variation in capture probabilities. Again, this simplification allowed us to directly evaluate the relationships between $p, r$, and $\sigma_{x}$. Unequal mean capture probabilities between HS and RT are similar to temporal variation in capture probabilities that can be modeled in MARK to minimize bias. In addition, the LP estimator has been shown to be robust to temporal variation in other studies (Menkens and Anderson 1988).

We simulated a population of 200 bears with mean persession capture probabilities ( $p$ ) of 0.1 and 0.2 and five sessions of concurrent HS and RT sampling. The population level of 200 was selected as an intermediate value between sex-specific and entire population estimates in the Greater Glacier Area. The levels of $p$ corresponded to the range of capture probabilities observed in our study. Per-session capture probabilities of 0.1 and 0.2 equate to pooled LP capture probabilities $\left(p_{\mathrm{LP}}\right)$ of 0.41 and 0.67 , respectively (using the formula $p_{\mathrm{LP}}$ $=1-\left(1-p_{\mathrm{j}}\right)^{s}$, where $s$ is the number of sessions (five). Using the $p_{\mathrm{LP}}$ formula with 10 sample sessions, the overall mean proportion of the population sampled was 0.65 and 0.89 , with per-session capture probabilities of 0.1 and 0.2 . We simulated correlations of hair snag and RT capture probabilities ranging from -1 to 1 and levels of $\mathrm{CV}_{p}$ of 0.15 and 0.4 . These $\mathrm{CV}_{p}$ levels resulted in approximately normal distributions of capture probabilities with ranges of $0.06-0.17$ and $0.02-0.29$, respectively (when $p=0.1$ ). As discussed later, simulations with $\mathrm{CV}_{p}=$ 0.4 best represents grizzly bear DNA mark-recapture data, whereas the $\mathrm{CV}_{p}$ of 0.1 demonstrate the effect of reduced heterogeneity on estimator performance. The following models were tested in simulations: the HSRTLP estimator, a HS-only two-point mixture model $\left[M_{\mathrm{h} 2} \pi(.) \theta_{1,2}().\right]$, a model with HS- and RT-specific capture probabilities $\left[M_{\mathrm{h}} p(\right.$ type $\left.)\right]$, and a two-point mixture model with HS- and RT-specific capture probability distributions $\left[M_{\mathrm{h} 2} \pi(.) \theta_{1,2}(\right.$ type $\left.)\right]$.

\section{RESULTS}

\section{Data summary}

Hair snagging was conducted mid-May to early August with 626 hair corrals deployed in 1998 and 633 deployed in 2000. Rub tree surveys were conducted from May until October with 602 and 828 rub trees sampled in 1998 and 2000, respectively. Rub tree survey effort was $3554 \pm 3863$ rub tree days per session (mean $\pm \mathrm{SD}$; $n=9$ sessions) in 1998 and $8559 \pm 3888$ rub tree days per session ( $n=12$ sessions) in 2000. Effort was lower in 1998 due to funding levels and addition of surveyed trees over the course of the 1998 season. And, while the distribution of trees was broadly comparable across years, areas surveyed were limited during early and late sessions. Rub tree surveys continued after hair snag sampling was completed for an additional four and six 14-d sampling periods in 1998 and 2000, respectively. The mean interval between visits to rub trees was $26.8 \pm$ $19.5 \mathrm{~d}(n=1193)$ in 1998 and $19.2 \pm 13.4 \mathrm{~d}(n=4344)$ in 2000.

Summary statistics from the LP model were calculated for the GNP study area where both RT and HS sampling occurred, as well as for the GGA study area, which contained large areas where no rub trees were sampled (Table 1, Fig. 1). Primarily due to lower rub tree sampling effort, relatively few individuals were detected in both HS and RT surveys (i.e., $m_{2}$ ) in 1998 leading to lower RT capture probabilities for both sexes than in 2000 (Table 1). The LP estimates suggest that female capture probabilities were higher for HS than for RT in both study areas in both years. Male HS capture probabilities were higher in 2000 than in 1998 in both study areas.

\section{Model selection}

Model selection results were similar for the GGA and GNP study areas. However, because sample sizes were larger for both HS and RT samples in the GGA area (Table 1), we focused our analysis on this area. Model selection results for the GNP area are provided in Appendices A and B.

\section{Greater Glacier Area: hair-snag-only data}

Model selection results for the HS data suggested that capture probabilities varied by sex (Table 2). In addition, there were linear trends in capture probabilities for females in 1998 and for both sexes in 2000 (Table 2, Fig. 2). Mean capture probabilities were low (i.e., model 1, 1998, males $\hat{p}=0.090$, females $\hat{p}=0.135$; 2000, males $\hat{p}=0.138$, females $\hat{p}=0.097)$. Undefined heterogeneity was not detected as indicated by low support of mixture models; however, low capture probabilities may have prevented its detection.

\section{Greater Glacier Area: joint hair-snag-rub-tree data}

Low numbers of female captures in early and late sessions for rub trees caused convergence issues with HUPL estimators. As a result, RT sessions 1-3 and 8-10 were pooled into two sessions resulting in six sessions for the 1998 RT data set. Sessions 10-12 were pooled for the 2000 data set, resulting in 10 RT sampling occasions.

Model selection results for the 1998 HSRT data suggested that capture probability varied by sex and changed linearly for HS data (Table 3, models 1-2). Rub tree capture probability varied by sex, changed linearly for males and females, and varied with RTE. Unlike HS 
TABLE 1. Lincoln-Petersen (LP) summary statistics for joint hair snag (HS) and rub tree (RT) sampling.

\begin{tabular}{|c|c|c|c|c|c|}
\hline \multirow{2}{*}{$\begin{array}{l}\text { Area, year, } \\
\text { and sex }\end{array}$} & \multicolumn{3}{|c|}{ No. captures } & \multicolumn{2}{|c|}{ LP estimates of capture probability } \\
\hline & $\mathrm{HS}\left(n_{1}\right)$ & $\mathrm{RT}\left(n_{2}\right)$ & $\operatorname{HSRT}\left(m_{2}\right)$ & HS $\left(m_{2} / n_{2}\right)$ & $\mathrm{RT}\left(m_{2} / n_{1}\right)$ \\
\hline \multicolumn{6}{|l|}{ GGA, 1998} \\
\hline Male & 56 & 37 & 15 & 0.41 & 0.27 \\
\hline Female & 91 & 25 & 16 & 0.64 & 0.18 \\
\hline \multicolumn{6}{|l|}{ GGA, 2000} \\
\hline Male & 70 & 81 & 43 & 0.53 & 0.61 \\
\hline Female & 85 & 54 & 25 & 0.46 & 0.29 \\
\hline \multicolumn{6}{|l|}{ GNP, 1998} \\
\hline Male & 40 & 14 & 3 & 0.21 & 0.08 \\
\hline Female & 73 & 13 & 7 & 0.54 & 0.10 \\
\hline \multicolumn{6}{|l|}{ GNP, 2000} \\
\hline Male & 46 & 65 & 30 & 0.46 & 0.65 \\
\hline Female & 61 & 25 & 10 & 0.40 & 0.16 \\
\hline
\end{tabular}

Notes: The numbers of unique bears identified in HS $\left(n_{1}\right)$ or RT $\left(n_{2}\right)$ samples and identified in both samples (HSRT; $m_{2}$ ) are used to provide estimates of LP capture probability. The study encompassed two nested study areas straddling the Continental Divide in northwestern Montana, USA. The Greater Glacier Area (GGA) statistics are based on five sessions of HS and 9-12 sessions of RT sampling in the GGA. The Glacier National Park (GNP, nested in the GGA) statistics are based only on the five concurrent sessions of HS and RT sampling in the GNP area.

data, undefined heterogeneity existed in the RT data set as shown by support for mixture models. For 2000, capture probabilities also varied by sex, type of capture, and RTE in addition to linear trends in capture probabilities for each sex and sample type. In contrast to 1998, mixture models that assumed undefined heterogeneity in both data types (models 1 and 2) were more supported than a model that assumed undefined heterogeneity only in the RT data (model 3). We presume this was a result of increased power to detect more complex forms of heterogeneity due to higher sample sizes. Various forms of the joint mixture model were also supported by the data (models 4 and 5). In both data sets, models that assumed no undefined heterogeneity in either data type were not supported (1998, model 6; 2000, model 11).

TABLE 2. Model selection results for hair-snag-only (HS-only) data in the 1998 and 2000 Greater Glacier Area (GGA).

\begin{tabular}{|c|c|c|c|c|c|c|}
\hline No. & Model & $\mathrm{AIC}_{\mathrm{c}}$ & $\Delta \mathrm{AIC}_{\mathrm{c}}$ & $w_{i}$ & $K$ & Deviance \\
\hline \multicolumn{7}{|c|}{1998} \\
\hline 1 & $p\left(\operatorname{sex}+T_{\mathrm{F}}\right)$ & 686.7 & 0.00 & 0.60 & 3 & 680.7 \\
\hline 2 & $p(\operatorname{sex} \times T)$ & 688.7 & 2.01 & 0.22 & 4 & 680.7 \\
\hline 3 & $p(\operatorname{sex} \times t)$ & 691.0 & 4.30 & 0.07 & 10 & 670.7 \\
\hline 4 & $\pi(.) \theta_{1,2}\left(+T_{\mathrm{F}}\right)$ & 691.6 & 4.92 & 0.05 & 6 & 679.5 \\
\hline 5 & $p()$. & 693.0 & 6.30 & 0.03 & 5 & 682.9 \\
\hline 6 & $\pi(.) \theta_{1,2}(\operatorname{sex} \times T)$ & 693.7 & 6.95 & 0.02 & 7 & 679.5 \\
\hline 7 & $\pi(\operatorname{sex}) \theta_{1,2}(\operatorname{sex} \times T)$ & 695.3 & 8.60 & 0.01 & 8 & 679.1 \\
\hline 8 & $p(\operatorname{sex}+t)$ & 695.6 & 8.94 & 0.01 & 7 & 681.5 \\
\hline \multicolumn{7}{|l|}{2000} \\
\hline 1 & $p(\operatorname{sex} \times T)$ & 744.1 & 0.00 & 0.26 & 4 & 736.1 \\
\hline 2 & $p()$. & 744.5 & 0.43 & 0.21 & 1 & 742.5 \\
\hline 3 & $p\left(\operatorname{sex} \times T_{\mathrm{F}}\right)$ & 744.6 & 0.51 & 0.20 & 3 & 738.6 \\
\hline 4 & $p(\operatorname{sex})$ & 745.0 & 0.87 & 0.17 & 2 & 741.0 \\
\hline 5 & $p(\operatorname{sex} \times t)$ & 747.4 & 3.29 & 0.05 & 10 & 727.1 \\
\hline 6 & $p(t)$ & 747.8 & 3.69 & 0.04 & 5 & 737.7 \\
\hline 7 & $\pi(.) \theta_{1,2}()$. & 748.1 & 3.98 & 0.04 & 3 & 742.1 \\
\hline 8 & $p(\operatorname{sex}+t)$ & 748.2 & 4.14 & 0.03 & 6 & 736.1 \\
\hline 9 & $\pi(\operatorname{sex}) \theta_{1,2}\left(\operatorname{sex}+T_{\mathrm{F}}\right)$ & 749.9 & 5.76 & 0.01 & 6 & 737.8 \\
\hline
\end{tabular}

Notes: A "+" refers to an additive term [i.e., $p(\operatorname{sex}+T) \cong \beta_{\text {int }}+\beta_{\text {sex }}+T$, where "int" stands for "intercept"], whereas a " $\times$ " refers to interactive terms [i.e., $p(\operatorname{sex} \times T) \cong \beta_{\text {int }}+\beta_{\text {sex }}+\beta_{T \mathrm{M}}+\beta_{T \mathrm{~F}}$, where "M" and "F" stand for "male" and "female," respectively], as discussed in White (2007). Sample-size-adjusted Akaike Information Criteria $\left(\mathrm{AIC}_{\mathrm{c}}\right)$, the difference in $\mathrm{AIC}_{\mathrm{c}}$ values between the $i$ th model and the model with the lowest $\mathrm{AIC}_{\mathrm{c}}$ value $\left(\Delta \mathrm{AIC}_{\mathrm{c}}\right)$, Akaike weights $\left(w_{i}\right)$, and number of parameters $(K)$ are presented. " $T$ " refers to a linear trend in capture probabilities; " $T_{\mathrm{F}}$ " refers to a linear trend for female bears only; " $t$ " refers to a time-specific model in which a unique capture probability is estimated for each sampling occasion. A "(.)" means the parameter was held constant (an intercept-only model). 
a) 1998 , hair snag samples

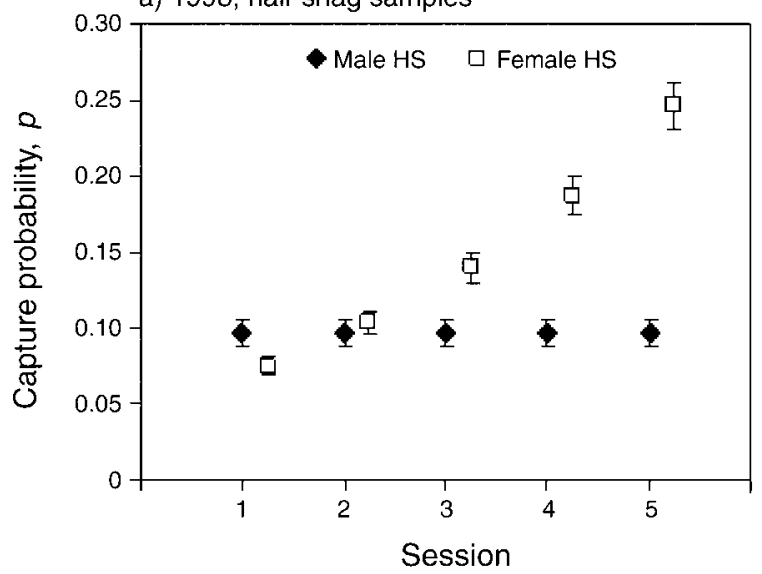

c) 1998 , rub tree samples

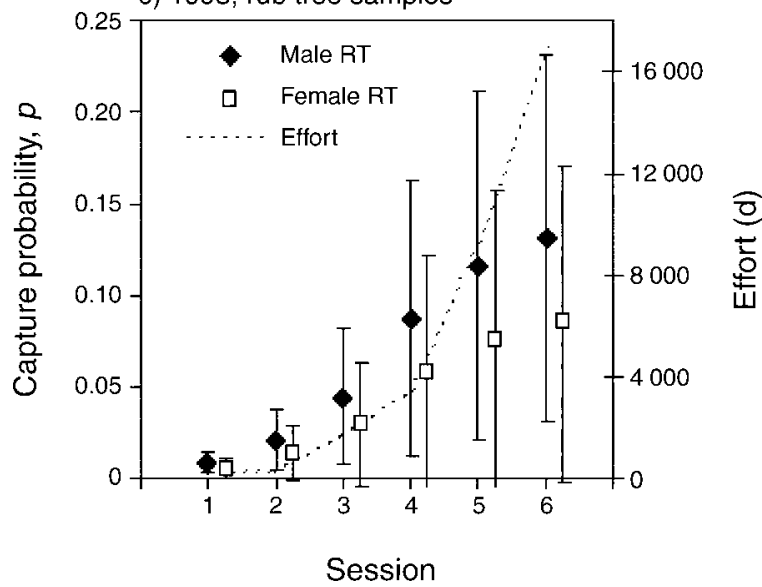

b) 2000 , hair snag samples

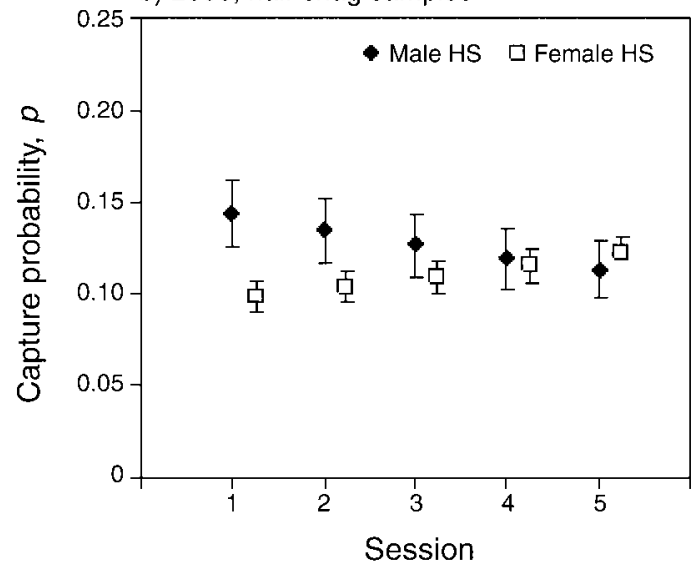

d) 2000 , rub tree samples

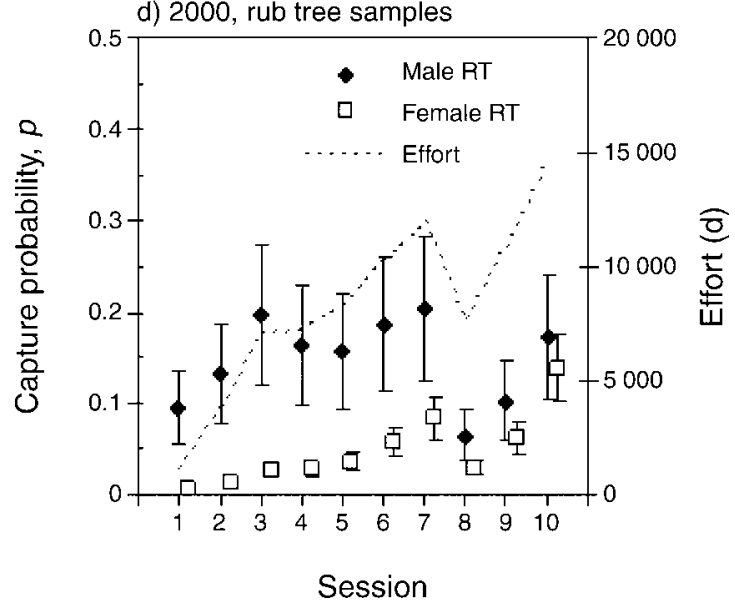

FIG. 2. Estimates of session-specific capture probability from hair snag (HS) and rub tree (RT) surveys in the Greater Glacier study area (GGA), 1998 and 2000. Estimates were model averaged from Huggins-Pledger (HUPL) $M_{\mathrm{h} 2}$ (mixture) models in Table 3. Rub tree effort (RTE) was the cumulative number of days between successive hair collections summed over every sampled tree per session.

Interpretation of within-year trends in RT capture probabilities was complicated by the lower amount of effort in initial rub tree surveys (Fig. 2). In 1998, RT capture probabilities increased with increased sampling effort. In 2000, capture probabilities were more variable partly due to variable sampling effort. The slope $(\beta)$ terms for temporal RT trends suggested increasing capture probabilities for females and decreasing capture probabilities for males. However, the confidence intervals overlapped zero for both sexes, suggesting that these trends were weak. The average CV of mixture probabilities for HS data in 1998 and 2000 from the most supported mixture models (Table 3 ) was 0.085 and 0.133 , whereas the average CV for RT data was 0.779 and 0.362 , respectively, indicating that heterogeneity was higher in RT samples.

\section{Population estimates}

Population estimates for the GGA from the HSHUPL and HSRT-HUPL estimators were higher than from the HSRT-LP (Fig. 3). The HSRT estimators displayed higher precision than the HS estimators in all years. However, as discussed later, correlation of capture probabilities could have resulted in negatively biased population size and variance estimates from the HSRT-LP estimator.

We also estimated population size for the GNP study area (Table 4) because rub tree sampling was primarily conducted in this area (Fig. 1). Small sample sizes resulting in low precision precluded solid comparison of estimates in 1998 (Table 1). In general, the magnitude and precision of estimates were similar for HS and HSRT models. The HSRT-HUPL model was the most precise of all estimators for both sexes in both years. Estimates using RT-only data were not possible for 1998 due to low sample sizes of bears (Table 1). The RT-only estimates for females in 2000 were significantly lower and less precise than for HS and HSRT estimates for the GNP area, whereas male estimates were only slightly 
TABLE 3. Model selection results for the joint hair-snag-rub-tree (HSRT) analysis, Greater Glacier Area (GGA), 1998 and 2000.

\begin{tabular}{|c|c|c|c|c|c|c|}
\hline No. & Model & $\mathrm{AIC}_{\mathrm{c}}$ & $\Delta \mathrm{AIC}_{\mathrm{c}}$ & $w_{i}$ & $K$ & Deviance \\
\hline \multicolumn{7}{|l|}{1998} \\
\hline 1 & HS: $p\left(\operatorname{sex}+T_{\mathrm{F}}\right) ; \mathrm{RT}: \pi(.) \theta_{1,2}\left(+\operatorname{sex}+T_{\mathrm{F}}+T_{\mathrm{M}}+\mathrm{RTE}\right)$ & 1292.9 & 0.00 & 0.433 & 10 & 1272.8 \\
\hline 2 & HS: $p\left(\operatorname{sex}+T_{\mathrm{F}}\right) ; \mathrm{RT}: \pi(\operatorname{sex}) \theta_{1,2}\left(+\operatorname{sex}+T_{\mathrm{F}}+T_{\mathrm{M}}+\mathrm{RTE}\right)$ & 1293.8 & 0.86 & 0.282 & 11 & 1271.6 \\
\hline 3 & $\pi(.) \theta_{1,2}\left(\times\right.$ type $\left.+\operatorname{sex}_{\mathrm{HS}}+\operatorname{sex}_{\mathrm{RT}}+T_{\mathrm{HS}-\mathrm{F}}+T_{\mathrm{RT}-\mathrm{M}}+T_{\mathrm{RT}-\mathrm{F}}+\mathrm{RTE}\right)$ & 1294.9 & 1.99 & 0.160 & 11 & 1272.7 \\
\hline 4 & $\pi(\operatorname{sex}) \theta_{1,2}\left(\times\right.$ type $\left.+\operatorname{sex}_{\mathrm{HS}}+\operatorname{sex}_{\mathrm{RT}}+T_{\mathrm{HS}-\mathrm{F}}+T_{\mathrm{RT}-\mathrm{M}}+T_{\mathrm{RT}-\mathrm{F}}+\mathrm{RTE}\right)$ & 1295.5 & 2.60 & 0.118 & 12 & 1271.3 \\
\hline 5 & $\pi(.) \theta_{1,2}(\operatorname{sex} \times$ type $\times T)$ & 1303.6 & 10.71 & 0.002 & 13 & 1277.4 \\
\hline 6 & $p($ sex $\times$ type $\times T+\mathrm{RTE})$ & 1303.7 & 10.81 & 0.002 & 9 & 1285.6 \\
\hline 7 & $\pi(\operatorname{sex}) \theta_{1,2}(\operatorname{sex} \times$ type $\times T)$ & 1304.5 & 11.58 & 0.001 & 14 & 1276.3 \\
\hline 8 & $p(\operatorname{sex} \times t)$ & 1306.0 & 13.09 & 0.001 & 22 & 1261.5 \\
\hline \multicolumn{7}{|l|}{2000} \\
\hline 1 & $\pi(.) \theta_{1,2}\left(\times\right.$ type $\left.+\operatorname{sex}_{\mathrm{HS}}+\operatorname{sex}_{\mathrm{RT}}+T_{\mathrm{RT} \times \operatorname{sex}}+T_{\mathrm{HS} \times \operatorname{sex}}+\mathrm{RTE}\right)$ & 2425.5 & 0.00 & 0.208 & 12 & 2401.4 \\
\hline 2 & $\pi(.) \theta_{1,2}\left(\times\right.$ type $\left.+\operatorname{sex}_{\mathrm{HS}}+\operatorname{sex}_{\mathrm{RT}}+T_{R T \times \operatorname{sex}}+\mathrm{RTE}\right)$ & 2426.4 & 0.88 & 0.133 & 10 & 2406.3 \\
\hline 3 & HS: $p(\operatorname{sex} \times T)$; RT: $\left.\pi(.) \theta_{1,2}+\operatorname{sex}+T_{\mathrm{RT}-\mathrm{F}}+T_{\mathrm{RT}-\mathrm{M}}+\mathrm{RTE}\right)$ & 2426.4 & 0.93 & 0.130 & 11 & 2404.4 \\
\hline 4 & $\pi(\operatorname{sex}) \theta_{1,2}\left(\times\right.$ type $\left.+\operatorname{sex}_{\mathrm{HS}}+\operatorname{sex}_{\mathrm{RT}}+T_{\mathrm{RT} \times \operatorname{sex}}+T_{\mathrm{HS} \times \operatorname{sex}}+\mathrm{RTE}\right)$ & 2426.7 & 1.23 & 0.112 & 13 & 2400.6 \\
\hline 5 & $\pi(.) \theta_{1,2}\left(\times\right.$ type $\left.+\operatorname{sex}_{\mathrm{RT}}+T_{\mathrm{RT} \times \operatorname{sex}}+\mathrm{RTE}\right)$ & 2427.0 & 1.48 & 0.099 & 10 & 2406.9 \\
\hline 6 & $\pi(.) \theta_{1,2}\left(\times\right.$ type $\left.\times \operatorname{sex}+T_{\mathrm{RT} \times \operatorname{sex}}+\mathrm{RTE}\right)$ & 2427.2 & 1.64 & 0.092 & 11 & 2405.1 \\
\hline 7 & $\pi(\operatorname{sex}) \theta_{1,2}(\times \operatorname{sex} \times$ type $\times T+\mathrm{RTE})$ & 2427.7 & 2.18 & 0.070 & 15 & 2397.5 \\
\hline 8 & HS: $p(\operatorname{sex} \times T) ; \mathrm{RT}: \pi(\operatorname{sex}) \theta_{1,2}\left(+\operatorname{sex}+T_{\mathrm{RT}-\mathrm{F}}+T_{\mathrm{RT}-\mathrm{M}}+\mathrm{RTE}\right)$ & 2428.1 & 2.60 & 0.057 & 12 & 2404.0 \\
\hline 9 & $\pi(.) \theta_{1,2}(\times$ sex $\times$ type $\times T+$ RTE $)$ & 2428.2 & 2.73 & 0.053 & 14 & 2400.1 \\
\hline 10 & $\pi(\operatorname{sex}) \theta_{1,2}\left(\times\right.$ type $\left.+\operatorname{sex}_{\mathrm{RT}}+T_{\mathrm{RT} \times \text { sex }}+\mathrm{RTE}\right)$ & 2428.6 & 3.04 & 0.045 & 11 & 2406.5 \\
\hline 11 & $p(\times$ sex $\times$ type $\times T+\mathrm{RTE})$ & 2461.0 & 35.46 & 0.000 & 11 & 2438.9 \\
\hline
\end{tabular}

Notes: Sample size-adjusted Akaike Information Criteria $\left(\mathrm{AIC}_{\mathrm{c}}\right)$, the difference in $\mathrm{AIC}_{\mathrm{c}}$ values between the $i$ th model and the model with the lowest $\mathrm{AIC}_{\mathrm{c}}$ value $\left(\Delta_{i}\right)$, Akaike weights $\left(w_{i}\right)$, and number of parameters $(K)$ are presented. Mixture models were only used for one of the data types if models are listed with "HS:" or "RT:". " $T$ " refers to a linear trend in capture probabilities. " $T_{\mathrm{F}}$ " and " $T_{\mathrm{M}}$ " refer to linear trends in capture probabilities for females or males, respectively. "RTE" refers to rub tree sampling effort (see Methods: Data analysis). "Type" refers to sampling type (hair snag or rub tree). "Sex $\mathrm{HS}$ " and "sex ${ }_{\mathrm{RT}}$ " refer to sex-specific capture probabilities for HS or RT. " $T_{\mathrm{HS} \times \text { sex }}$ " and " $T_{\mathrm{RT} \times \text { sex }}$ " refer to sex-specific trends for HS or RT data types. " $T_{\mathrm{RT}-\mathrm{F}}$, " " $T_{\mathrm{RT}-\mathrm{M}}$," " $T_{\mathrm{HS}-\mathrm{F}}$," and " $T_{\mathrm{HS}-\mathrm{M}}$ " refer to a linear trend in capture probabilities for female RT, male RT, female HS, and male HS, respectively.

lower (Table 4), suggesting that some female bears had zero RT capture probability.

\section{Simulation results}

The robustness of estimators to correlation in HS and RT capture probabilities was influenced substantially by mean capture probability levels and the degree of heterogeneity variation simulated. The capture probabilities and estimated levels of heterogeneity from the mixture models (from the GGA analysis) and levels of heterogeneity observed in other hair-snag-based DNA mark-recapture studies (Boulanger et al. 2002) suggest that simulations with sparse data $\left(p=0.1, p_{\mathrm{LP}}=0.41\right)$ and substantial $\left(\mathrm{CV}_{p}=0.4\right)$ heterogeneity were most applicable to the data in this study.

When data were sparse and heterogeneity substantial, the LP and most HSRT estimators showed a negative bias that increased as correlation increased (Fig. 4). The least bias occurred when correlation was 0 (no relationship between HS and RT capture probabilities). With correlation ranging from -1 to +1 , model $M_{\mathrm{h} 2} \pi\left(\right.$.) $\theta_{1,2}$ (type) was moderately robust with bias ranging from $2.7 \%$ to $-2.3 \%$, model $M_{\mathrm{h}} p$ (type) was less robust with bias ranging from $1.3 \%$ to $-9.1 \%$, and the LP estimator was the least robust of the HSRT models, with bias extending from $10.7 \%$ to $-7.8 \%$. Because it was not affected by correlation of HS and RT capture probabilities, the HS-only mixture model was one of the least biased when $r=1$; however, it did not converge in $\sim 30 \%$ of the simulations due to instability of the mixture estimator in MARK when the number of sessions is low. The precision of HSRT estimators was higher than the HS-only estimator in all simulations (Appendix C). Confidence interval coverage for the LP estimator was only near $95 \%$ when $r$ was close to 0 , with sparse data $(p=0.1)$ and substantial heterogeneity; only the $M_{\mathrm{h}} p$ (type) model had poorer coverage when $r=1$. The HSRT $M_{\mathrm{h} 2} \pi(.) \theta_{1,2}$ (type) maintained confidence limits around $90 \%$ across the range of correlations.

Estimators exhibited less bias when mean per-session capture probability was increased from 0.1 to 0.2 or when heterogeneity was reduced from 0.4 to 0.15 (Appendix C). One exception was the HS-only mixture model, which showed a positive bias when heterogeneity was low and data were sparse. Confidence interval coverage was still slightly reduced for the LP and HSRT $M_{\mathrm{h}} p$ (type) when $r$ was close to 1 .

The performance of estimators when a segment of bears had zero capture probability in the RT sample was affected by mean capture probability and the degree of heterogeneity simulated (Fig. 5, Appendix D), similar to the heterogeneity scenario. The LP estimator displayed comparable performance to simulations in which all bears had nonzero capture probabilities. The model $M_{\mathrm{h} 2} \pi(.) \theta_{1,2}$ (type) was still moderately robust with similar levels of bias (at approximately -5\%) across the range of correlations when heterogeneity was high $\left(\mathrm{CV}_{p}=0.4\right)$ and was nearly unbiased when $\mathrm{CV}_{p}=0.15$. Confidence interval coverage was substantially reduced for model HSRT $M_{\mathrm{h}} p$ (type) estimators, especially when 

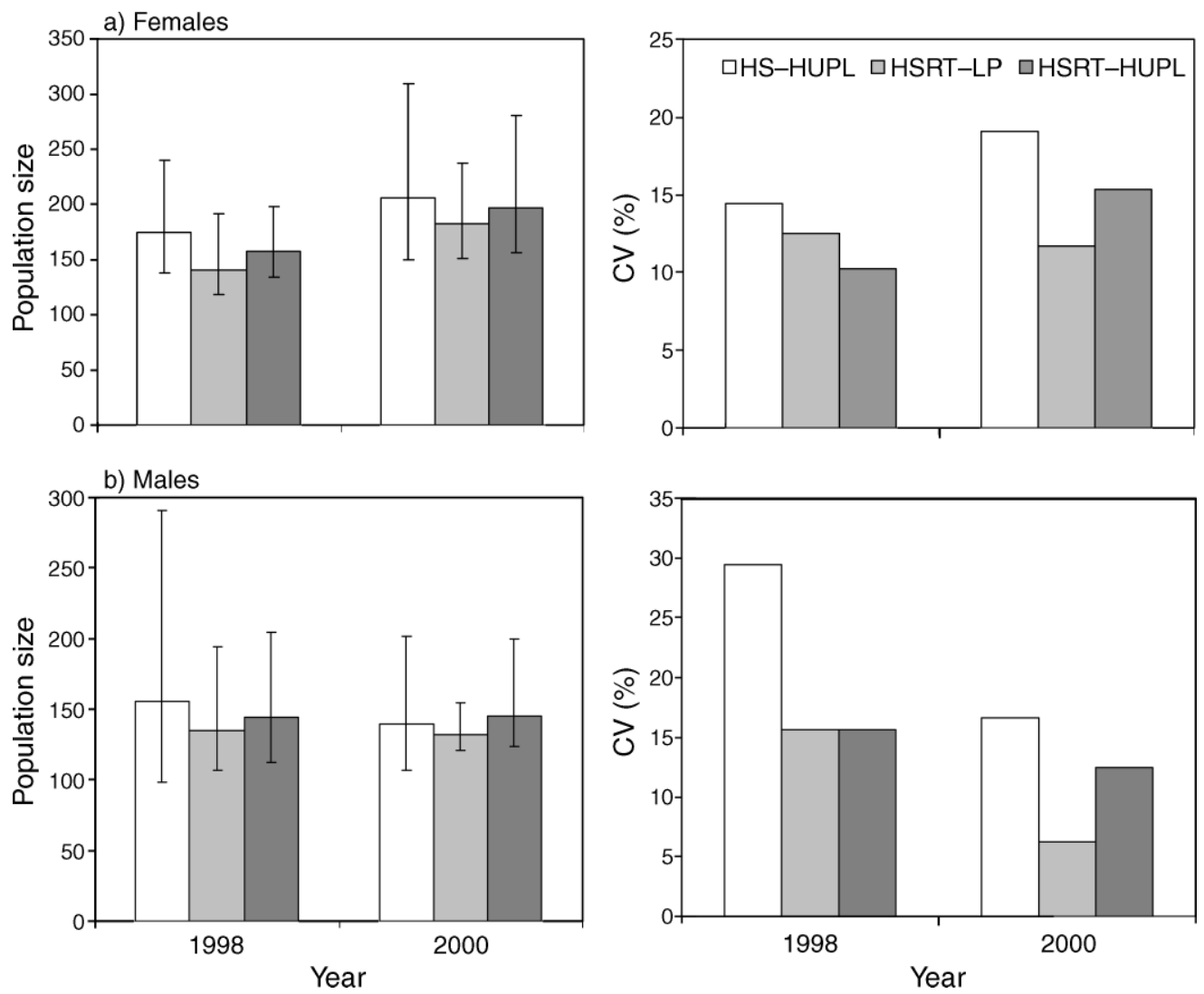

FIG. 3. Grizzly bear population estimates (HS-HUPL, hair snag, Huggins-Pledger model; HSRT-LP, hair-snag-rub-tree, Lincoln-Petersen model; HSRT-HUPL, hair-snag-rub-tree, Huggins-Pledger model) and associated precision (coefficient of variation) for the Greater Glacier Area (GGA), 1998 and 2000. Huggins-Pledger estimates were model averaged from models in Tables 2 and 3 and Appendix A. Error bars indicate 95\% confidence intervals for population estimates.

capture probabilities and heterogeneity were high $(p=$ 0.2 and $\mathrm{CV}_{p}=0.4$; Appendix D).

\section{DisCussion}

\section{General comments}

The methodology we developed in this manuscript offers a way to potentially increase sample coverage and estimator robustness by supplementing mark-recapture analyses with information from other less expensive sources. While our study focuses on rub trees and hair snags, we suggest that the general principles developed in this paper could be applied to other species. For example, scat sampling (Bellemain et al. 2005), radio telemetry (Powell et al. 2000), and sightings (White 1996) have been used in combination with traditional mark-recapture methods to estimate population size. The main constraint in the application of this technique is the degree in which data sources are correlated. If correlation is minimal, simple Lincoln-Peterson methods may be adequate. If correlation and heterogeneity exist, more complex mark-recapture models may be needed. However, even in the latter case, estimates are improved by the incorporation of multiple data sources.
TABle 4. Population estimates for Glacier National Park, 1998 and 2000.

\begin{tabular}{llrrrr}
\hline \hline Data & Estimator & Estimate & SE & CV & $95 \%$ CI \\
\hline 1998, female & & & & & \\
HS & HUPL & 153 & 26.4 & 17.3 & 116,223 \\
HSRT & HUPL & 142 & 19.7 & 13.8 & 114,194 \\
HSRT & LP & 130 & 26.7 & 20.6 & 98,213 \\
1998, male & & & & & \\
HS & HUPL & 107 & 33.7 & 31.6 & 66,210 \\
HSRT & HUPL & 129 & 31.3 & 24.3 & 88,217 \\
HSRT & LP & 154 & 55.9 & 36.4 & 89,330 \\
2000, female & & & & & \\
HS & HUPL & 153 & 36.0 & 23.6 & 105,254 \\
HSRT & HUPL & 154 & 25.7 & 16.7 & 118,222 \\
HSRT & LP & 147 & 29.1 & 19.8 & 109,230 \\
RT & HUPL & 82 & 54.3 & 66.2 & 37,300 \\
2000, male & & & & & \\
HS & HUPL & 92 & 18.8 & 20.5 & 67,145 \\
HSRT & HUPL & 94 & 5.1 & 5.4 & 87,108 \\
HSRT & LP & 100 & 7.5 & 7.5 & 90,121 \\
RT & HUPL & 81 & 7.3 & 9.0 & 72,103 \\
\end{tabular}

Notes: All Huggins-Pledger (HUPL) estimates are model averaged from models in Appendix A. Rub tree (RT)-only estimates for 2000 were made using model $M_{\mathrm{h} 2} \pi(.) \theta_{1,2}(\operatorname{sex} \times T)$ + RTE. Low sample sizes precluded RT-only estimates for 1998. 

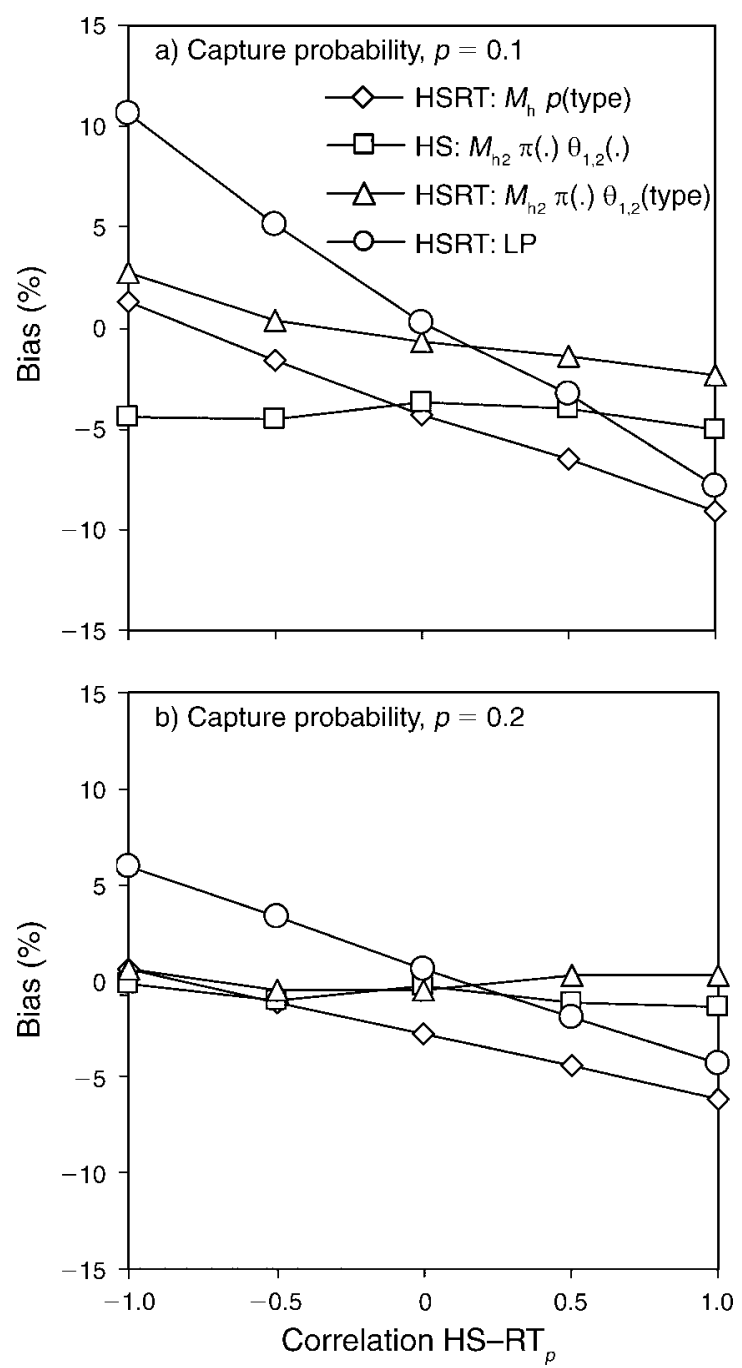

FIG. 4. Performance of estimators when heterogeneity variation is substantial $\left(\mathrm{CV}_{p}=0.4\right)$. Simulations from (a) sparse data (capture probability, $p=0.1$; Lincoln-Petersen estimator, $\left.p_{\mathrm{LP}}=0.41\right)$ and (b) less sparse data $\left(p=0.2, p_{\mathrm{LP}}=\right.$ $0.67)$ are shown. All estimators used five sessions of hair snag (HS) and five sessions of rub tree (RT) data except for the HSonly estimator, which only used five sessions of HS data.

Our results found that joint hair-snag-rub-tree sampling improves population estimates over HS-only surveys if minimal sampling requirements for both data types are satisfied. The HS-only estimates from this study were relatively imprecise due to low capture probabilities. Incorporation of the RT data increased sample size and overall coverage of marked animals with subsequent gains in estimate precision. Increasing sampling coverage also reduced heterogeneity leading to greater robustness of estimators when capture probabilities were higher. In general, the HS-only and the HSRT-HUPL estimates were higher than the HSRT-LP estimates (Fig. 3) for the GGA data set. Empirical comparisons were limited by low capture probabilities that restricted our ability to detect and model heterogeneity variation. Due to this and because it is not possible to infer bias from empirical trials, simulations were used to evaluate these effects on the estimators. Sparse data simulations showed that joint HSRT estimators can be biased when data are sparse and capture probabilities are correlated (Figs. 4 and 5).

The general correspondence between HS-only and HSRT estimates suggests that HS-only estimates target the same general cohorts of bears that are targeted by HSRT sampling. For example, if HS sampling "missed" a segment of bears, HSRT estimates would be substantially higher. The low number of bears captured in both sample types in Table 1 may seem to suggest that hair
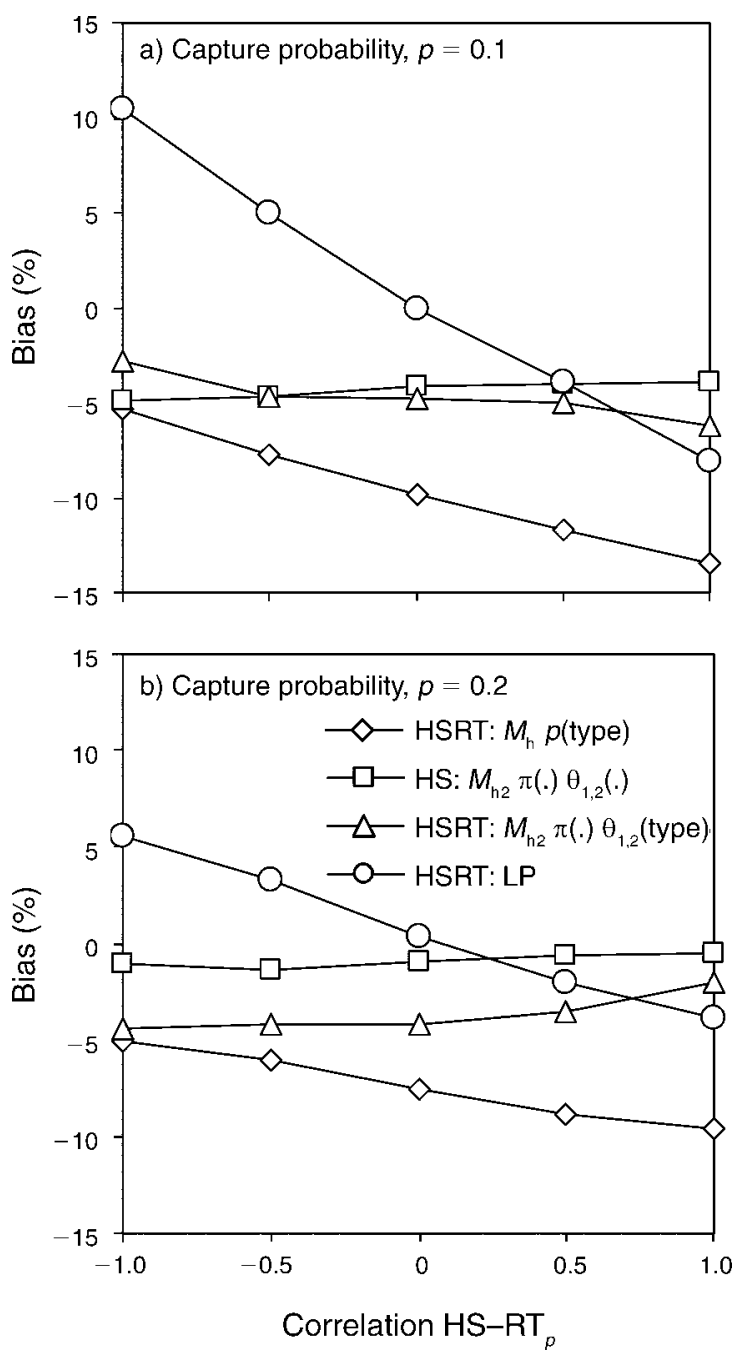

FIG. 5. Performance of estimators when heterogeneity variation is substantial $\left(\mathrm{CV}_{p}=0.4\right)$ and $33 \%$ of the bears have zero capture probability $(p)$ in the rub tree sample. Simulations from (a) sparse data ( $p=0.1$; Lincoln-Petersen estimator, $p_{\mathrm{LP}}=$ $0.41)$ and (b) less sparse data $\left(p=0.2, p_{\mathrm{LP}}=0.67\right)$ are shown. All estimators used five sessions of hair snag (HS) and five corresponding sessions of rub tree (RT) data except for the HSonly estimator, which only used five sessions of HS data. 

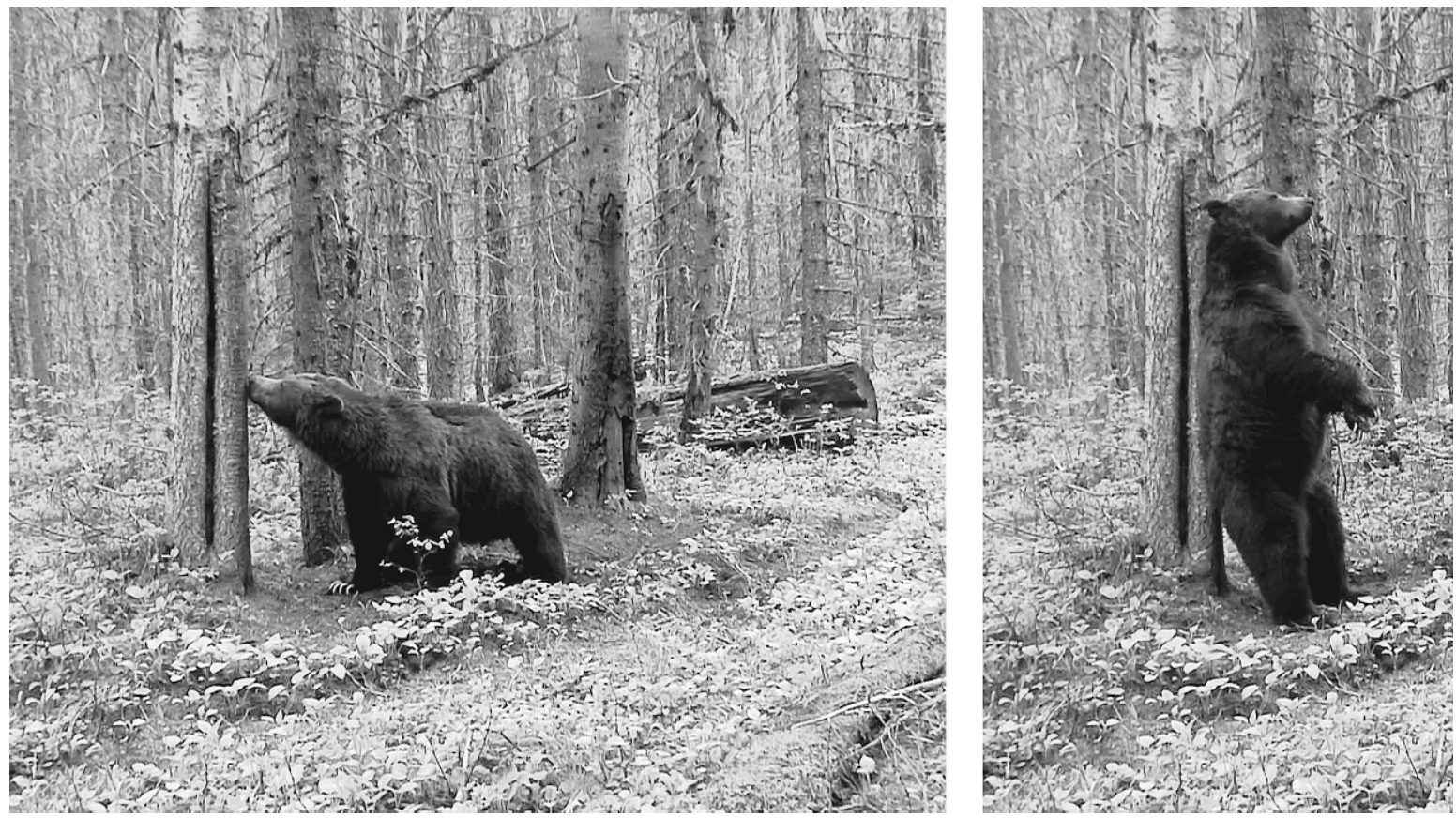

Plate 1. A wild grizzly bear investigating and rubbing on a tree along a maintained hiking trail in Glacier National Park, Montana, USA. Note the obvious discoloration due to rubbing activity on a second tree to the right of the bear. Also visible is a path worn by bears walking between these rubs. Genotyping hair samples from bear rubs in conjunction with video documentation has shown that multiple bears will rub on these trees over even short time periods, and a given bear may use the same rubs for many years. Images were pulled from motion-activated high-definition video. Footage by J. B. Stetz, courtesy of the U.S. Geological Survey.

snags and rub trees sample unique segments of the population; however, this is more due to overall low capture probabilities than sampling bias with the HS technique. In contrast, it is likely that some cohorts had minimal or zero capture probabilities with RT sampling, as suggested by reduced RT-only abundance estimates for females for the 2000 GNP study area. These results support use of hair snags as the primary sample for abundance estimation studies, with rub trees used as a lower-cost method of improving the estimate than increasing hair snag grid sampling intensity.

\section{Comparison of estimators}

In general, the model-averaged HSRT-HUPL estimator displayed better performance than the HSRT-LP and HS-HUPL estimators, producing estimates of similar magnitude, often with greater precision. This was because the HSRT-HUPL estimator utilized the most information from the encounter history data set. The HSRT-HUPL analysis also documented temporal trends in the data set, i.e., increasing female and decreasing male HS capture probabilities in 2000. In addition, undefined heterogeneity (Table 3 ) was documented, suggesting that factors other than sampling type, rub tree effort, temporal trend, and sex influenced capture probabilities. Simulation results further indicated that HUPL model $M_{\mathrm{h} 2} \pi(.) \theta_{1,2}$ (type) was most robust to correlation between HS and RT capture probabilities when heterogeneity was high, as is typical of bear hair snagging data sets (Fig. 4). This is likely due to the fact that session-specific information was used to estimate semi-independent two-point capture probability distributions for HS and RT samples or two-point distributions for the RT data set, thereby minimizing the linkage between the two data types. A more significant effect of correlations between HS and RT capture probabilities was decreased confidence interval coverage $(\sim 80 \%$ as $r$ approached 1; Appendix C). This most likely was due to overdispersion of multinomial variances caused by nonindependence of HS and RT capture probabilities. The HSRT-HUPL mixture models assumed a shared probability of mixture that might limit the ability of the models to accommodate more complex forms of heterogeneity variation. However, support for pooled probability of mixture for sex-specific analyses and overall support of mixture models (compared to nonmixture models; Table 3) suggests that the assumption of a common probability of mixture was reasonable in our analysis.

The HSRT-LP estimator displayed lower estimates for females in GNP, lower estimates for both sexes in the GGA, and more precise estimates for the 2000 GGA and GNP data compared to the HS-only and HSRTHUPL estimators (Fig. 3, Table 4). However, simulations found that LP population and variance estimates were more influenced than other estimators by correla- 
tion between HS and RT capture probabilities when there were high levels of heterogeneity and low capture probabilities $\left(p_{\mathrm{LP}}=0.41\right.$; Fig. 4$)$. With positive correlation between data types, the number of bears captured by both HS and RT increases, causing a positive bias in capture probability and negative bias in population size. With negative correlation, the number of bears captured by both HS and RT sampling methods is reduced, causing capture probability to be underestimated and a positive bias in estimates. It is likely there was a moderate positive correspondence between RT and HS capture probabilities in our data set. For example, males that move a lot could encounter more hair snag sites (Boulanger et al. 2004a) as well as rub trees, creating a positive correlation between their capture probabilities. In addition, female use of both hair snags and rub trees increased as the sampling period progressed. Positive correlation of capture probabilities could explain why LP estimates usually were lower than the HS-only and HSRT-HUPL estimates for the GGA area. Given this, the higher precision observed for the LP estimator was likely due to an underestimate of variance. Therefore, we argue that for our data, the advantages of the LP estimator are outweighed by nonrobustness to correlations in HS and RT capture probabilities when data are sparse and heterogeneity is present in the data set, as it is with most bear hair snag studies (Boulanger et al. 2002).

The LP estimator is unbiased when there is no correlation between HS and RT capture probabilities and heterogeneity is minimal or when mean capture probability is high enough so that a substantial proportion of the population is captured. This assumes that capture probability is greater than zero for all bears in at least one of the sampling methods. When these conditions are met, the LP estimator may be a more efficient and less expensive way to obtain robust population estimates in the presence of heterogeneity by allowing less-structured sampling designs. While our data did not meet these requirements, they may be adequately met with other species or other sampling methods and designs.

\section{Study design considerations}

Our paper is focused on grizzly bear DNA markrecapture data; however, the general findings apply to any study that employs multiple data sources. Results of simulations and empirical trials suggest that multiple sampling types can be employed even when sampling using one type is not conducted over the entire study area. However, this method still assumes that all individuals have a nonzero capture probability in at least one of the data types. This assumption is most likely met with DNA-based bear studies if hair snag sampling is intensive enough to ensure that all bears have the opportunity to encounter a hair corral (Boulanger et al. 2004a, $b$, 2006). In addition, sampling should ensure adequate numbers of animals are captured in both sample types for the LP estimator or adequate recaptures by the secondary sampling method to allow the use of mixture models that are robust to heterogeneity. We suggest that future studies (1) sample intensively enough to ensure adequate capture probabilities, i.e., $p \geq 0.2$ with each sampling method, (2) synchronize the area covered by sampling types to minimize heterogeneity, and (3) consider seasonal behavior to target sampling periods that optimize capture probabilities among sampling methods. For instance, HS and RT capture probabilities generally increased for both sexes as the sample season progressed. The relatively simple simulation model presented in this paper provides a useful way to explore sampling intensities needed to ensure reliable performance of multiple data source estimators.

\section{ACKNOWLEDGMENTS}

Gary White (Colorado State University, Ft. Collins, Colorado) provided useful feedback on analyses and the initial motivation for the use of MARK estimators for joint HSRT data. Kim Keating (NoRock Science Center, U.S. Geological Survey, Bozeman, Montana), Gary White, and Kevin McKelvey (Rocky Mountain Research Station, USDA Forest Service, Missoula, Montana) provided useful comments on earlier versions of this manuscript. Funding for this project was provided by the U.S. Geological Survey, National Park Service NRPP and CCS programs, McIntyre-Stennis funds, National Fish and Wildlife Foundation, Canon Corporation, EarthWatch Institute, and the U.S. Forest Service. In-kind support was provided by Glacier National Park, Blackfeet Nation, Montana Department of Natural Resource and Conservation, Flathead, Kootenai, and Lewis and Clark National Forests, Montana Department of Fish, Wildlife, and Parks, and the Student Conservation Association.

\section{Literature Cited}

Bellemain, E., J. E. Swenson, D. Tallmon, S. Brunberg, and P. Taberlet. 2005. Estimating population size of elusive animals with DNA from hunter-collected feces: four methods for brown bears. Conservation Biology 19:150-161.

Boersen, M. R., J. D. Clark, and T. L. King. 2003. Estimating black bear population density and genetic diversity at Tensas River, Louisiana using microsatellite DNA markers. Wildlife Society Bulletin 31:197-207.

Boulanger, J., M. Proctor, S. Himmer, G. Stenhouse, D. Paetkau, and J. Cranston. 2006. An empirical test of DNA mark-recapture sampling strategies for grizzly bears. Ursus 17:149-158.

Boulanger, J., G. Stenhouse, and R. Munro. 2004a. Sources of heterogeneity bias when DNA mark-recapture sampling methods are applied to grizzly bear (Ursus arctos) populations. Journal of Mammalogy 85:618-624.

Boulanger, J., G. C. White, B. N. McLellan, J. G. Woods, M. F. Proctor, and S. Himmer. 2002. A meta-analysis of grizzly bear DNA mark-recapture projects in British Columbia. Ursus 13:137-152.

Boulanger, J., J. Woods, B. N. McLellan, M. F. Proctor, and C. Strobeck. 2004b. Sampling design and capture probability bias in DNA based mark-recapture estimates of grizzly bear populations. Journal of Wildlife Management 68:457-469.

Brown, D., and P. Rothery. 1993. Models in biology: mathematics, statistics, and computing. John Wiley and Sons, New York, New York, USA.

Burnham, K. P., and D. R. Anderson. 1998. Model selection and inference: a practical information theoretic approach. Springer, New York, New York, USA. 
Burnham, K. P., D. R. Anderson, G. C. White, C. Brownie, and K. H. Pollock. 1987. Design and analysis methods for fish survival experiments based on release-recapture. American Fisheries Society, Bethesda, Maryland, USA.

Burst, T. L., and M. R. Pelton. 1983. Black bear mark trees in the Smoky Mountains. International Conference on Bear Research and Management 5:45-53.

Carothers, A. D. 1973. The effects of unequal catchability on Jolly-Seber estimates. Biometrics 29:79-100.

Ennis, S., and T. F. Gallagher. 1994. PCR based sex determination assay in cattle based on the bovine Amelogenin locus. Animal Genetics 25:425-427.

Green, G. I., and D. J. Mattson. 2003. Tree rubbing by Yellowstone grizzly bears Ursus arctos. Wildlife Biology 9:1-9.

Huggins, R. M. 1991. Some practical aspects of a conditional likelihood approach to capture experiments. Biometrics 47: 725-732.

Kendall, K. C., L. H. Metzgar, D. A. Patterson, and B. M. Steele. 1992. Power of sign surveys to monitor population trends. Ecological Applications 2:422-430.

Lincoln, F. C. 1930. Calculating waterfowl abundance on the basis of banding returns. U.S. Department of Agriculture Circular 118:1-4.

Menkens, G. E. J., and S. H. Anderson. 1988. Estimation of small-mammal population size. Ecology 69:1952-1959.

Mowat, G., D. C. Heard, D. R. Seip, K. G. Poole, G. Stenhouse, and D. Paetkau. 2005. Grizzly Ursus arctos and black bear $U$. americanus densities in the interior mountains of North America. Wildlife Biology 11:31-48.

Otis, D. L., K. P. Burnham, G. C. White, and D. R. Anderson. 1978. Statistical inference from capture data on closed animal populations. Wildlife Monographs 62:1-135.

Paetkau, D. 2003. An empirical exploration of data quality in DNA-based population inventories. Molecular Ecology 12: 1375-1387.

Paetkau, D., W. Calvert, I. Stirling, and C. Strobeck. 1995. Microsatelite analysis of population structure in Canadian polar bears. Molecular Ecology 4:347-354.

Pledger, S. 2000. Unified maximum likelihood estimates for closed models using mixtures. Biometrics 56:434-442.
Powell, L. A., M. Conroy, J. E. Hines, J. D. Nichols, and D. G. Krementz. 2000. Simultaneous use of mark-recapture and radiotelemetry to estimate survival, movement, and capture rates. Journal of Wildlife Management 64:302-313.

Roon, D. A., L. Waits, and K. C. Kendall. 2005. A simulation test of the effectiveness of several methods for error-checking non-invasive genetic data. Animal Conservation 8:203-215.

Seber, G. A. F. 1982. The estimation of animal abundance. Charles Griffin, London, UK.

Taberlet, P., H. Mattock, C. Dubois-Paganon, and J. Bouvet. 1993 Sexing free-ranging brown bears Ursus arctos using hairs found in the field. Molecular Ecology 2:399-403.

Triant, D. A., R. M. Pace, and M. Stine. 2004. Abundance, genetic diversity and conservation of Louisiana black bears (Ursus americanus luteolus) as detected through noninvasive sampling. Conservation Genetics 5:647-659.

Waits, L. P., and D. Paetkau. 2005. Noninvasive genetic sampling tools for wildlife biologists: a review of applications and recommendations for accurate data collection. Journal of Wildlife Management 69:1419-1433.

White, G. C. 1996. NOREMARK: Population estimation from mark-resighting surveys. Wildlife Society Bulletin 24:50-52.

White, G. C. 2007. Closed population models and their extensions in program MARK. Environmental and Ecological Statistics, in press.

White, G. C., and K. P. Burnham. 1999. Program MARK: Survival estimation from populations of marked animals. Bird Study Supplement 46:120-138.

White, G. C., K. P. Burnham, and D. R. Anderson. 2002. Advanced features of program MARK. Pages 368-377 in R. Fields, R. J. Warren, H. Okarma, and P. R. Seivert, editors. Integrating people and wildlife for a sustainable future: Proceedings of the second International Wildlife Management Congress, Gödölló, Hungary. Wildlife Society, Bethesda, Maryland, USA.

Williams, B. K., J. D. Nichols, and M. J. Conroy. 2002. Analysis and management of animal populations. Academic Press, San Diego, California, USA.

Woods, J. G., D. Paetkau, D. Lewis, B. N. McLellan, M. Proctor, and C. Strobeck. 1999. Genetic tagging free ranging black and brown bears. Wildlife Society Bulletin 27:616-627.

\section{APPENDIX A}

Huggins-Pledger closed model selection for hair-snag-only data for Glacier National Park, Montana, USA, 1998 and 2000 (Ecological Archives A018-017-A1).

\section{APPENDIX B}

Huggins-Pledger closed model selection for hair snag and rub tree data for Glacier National Park, Montana, USA, 1998 and 2000 (Ecological Archives A018-017-A2).

\section{APPENDIX C}

Model performance in simulations as a function of mean capture probability level, correlation between hair snag and rub tree capture probabilities, and heterogeneity variation when capture probability $>0$ for all bears in both data types (Ecological Archives A018-017-A3).

\section{APPENDIX D}

Model performance in simulations as a function of mean capture probability level, correlation between hair snag and rub tree capture probabilities, and heterogeneity variation when rub tree capture probability $=0$ for $33 \%$ of bears (Ecological Archives A018-017-A4). 